\title{
Co-creation in citizen social science: the research forum as a methodological foundation for communication and participation
}

\author{
Stefan Thomas ${ }^{1 凶}$, David Scheller ${ }^{1 凶} \&$ Susan Schröder ${ }^{1}$
}

This paper addresses the emerging methodological debate about citizen social science from the perspective of participatory research methods. The paper introduces the research forum as a horizontal and safe communicative space moderated by academic researchers that enables co-researcher participation across all phases of co-creational research projects. It is argued that in co-creational citizen social science, such a communicative space requires conceptualisation in order for it to foster citizens' engagement in the knowledge production that deals with their specific social lifeworlds. In the research forum, the potential that the social sciences bring to citizen science-methodological reflection and the theoretical interpretation and contextualisation of data-can flourish in a collaborative process. Based on the expertise in co-created research in multigenerational co-housing projects, the paper reflects on practical experiences with the research forum in terms of four central dimensions: (1) opening up spaces for social encounters; (2) establishing communicative practice; (3) initiating a process of social self-understanding; (4) engaging in (counter-)public discourses. Finally, the paper closes with a summary of potential and challenges that the research forum provides as a methodological foundation for co-creation in citizen social science projects.

\footnotetext{
${ }^{1}$ University of Applied Sciences Potsdam, Potsdam, Germany. ${ }^{凶}$ email: stefan.thomas@fh-potsdam.de; david.scheller@fh-potsdam.de
} 


\section{Introduction}

$\mathrm{n}$ recent years, the number of citizen science projects, and the public recognition of citizen science, has increased significantly (Sauermann et al., 2020). Citizen science has an over three-decade history, and has been primarily conducted in the natural sciences. In recent years, however, there has been an increase in discourses on the role of the social sciences in citizen science (Kullenberg and Kasperowski, 2016; Tauginiené et al., 2020; Pettibone and Ziegler, 2016). The emerging field of citizen social science brings together social science researchers who conduct citizen science projects (Dadich, 2014; Purdam, 2014; Kythreotis et al., 2019; Heiss and Matthes, 2017) and researchers with a background in citizen science who focus on social issues and thus apply and integrate social science methodologies and theories in research (Darch, 2017; Eitzel et al., 2017; Hecker et al., 2018; Mayer et al., 2021; Vohland et al., 2021). These two streams converge in considering the role of citizens' social concerns as a central aspect that requires reflection on various degrees of participation and involvement of citizens as co-researchers (Eleta et al., 2019; Mayer et al., 2018; Bonhoure et al., 2019; Senabre et al., 2018). In the following, we use the term "co-researcher" for people that conduct research in a citizen science project-alone or together with academic researchers (Whyte, 1990) and the term "co-researcher communication" for mutual exchange between the project partners.

From the very beginning, citizen science has served as an umbrella term for a broad variety of approaches to citizen participation in research (Shirk et al., 2012; Phillips et al., 2019). Two perspectives on participation-a key concept in citizen sciencehave developed. The first perspective is especially concerned with the democratisation of science by renegotiating the relationship between science and technology, on the one hand, and society and the public, on the other, and by empowering participatory grassroots research (Irwin, 1995; Kasemir et al., 2003; Leshner, 2003; Powell and Collin, 2009; Ottinger, 2010). The second perspective adopts a rather top-down, scientist-led crowd science approach that aims to involve citizens in large numbers in the data collection and analysis (Bonney et al., 2009; Bonney et al., 2014; Franzoni and Sauermann, 2014). Notwithstanding this duality of approaches, citizen participation in science is a topic that has acquired new relevance in recent years because, as Maasen and Lieven (2006) noted, "a general shift is seen to be taking place from a legitimation through knowledge to a legitimation through participation" (p. 400; emphasis in the original).

Papers that use the term "citizen social science" include a broad variety of levels of co-researcher participation and engagement ranging from data collection by citizen research volunteers about people begging in the streets of London (Purdam, 2014), through co-creational research on mental health issues together with affected people in Barcelona (Bonhoure et al., 2019), to accelerating climate action and awareness of climate policies through increased citizen engagement (Kythreotis et al., 2019). Various tools and approaches, for example, co-evaluation, are used to enhance the research outcomes (Mayer et al., 2021).

The inclusion of a multitude of perspectives by strengthening the discourse between (civil) society and science leads not only to an increase in knowledge production but also to a different type of knowledge that can contribute to finding more sustainable solutions for practical societal challenges and problems. In cocreated research, citizens can draw up their own research agendas by pursuing research interests that they have defined and that are not always covered by academic disciplines and research paradigms (Hecker et al., 2018). This can improve self-determination and action potency through evidence-based knowledge that can be transformed into social practices to solve societal issues and problems. Co-creation-oriented citizen social science projects, in particular, emphasise the importance of face-to-face communication in "participatory meetings" (Senabre-Hidalgo et al., 2021). The authors stressed the potential of such communicative spaces facilitated by academic researchers for reflecting on ethical dimensions of research, such as the co-researchers' and academic researchers' hidden agendas. However, a methodological conceptualisation of these spaces remains rather implicit. Against this background, we argue that an explicit discussion of the foundational methodology that guides communication between project partners is of key importance in co-creational citizen social science projects. The communicative and discursive turn in social and political science seems to be promising to further elaborate on such a framework (Habermas, 1985; Kemmis and McTaggart, 2005). With social concerns of the co-researchers put at the centre of the research, we consider co-researcher communication essential for the co-creation process itself. Appropriate communication leads to ongoing exchange and reflection between all stakeholders of the research, for example regarding the research design (i.e., question, steps, aims), research ethics (i.e., informed consent, data protection, intellectual property) and practical effects on the co-researchers (i.e., community building, conflicts).

In the following, we are laying out a methodological framework of the research forum as an approach to co-creational citizen social science. First, by drawing on different theories, we provide a methodological conceptualisation of the research forum as an open, safe, inclusive, and horizontal space for co-researcher communication in all phases of the research. The characteristics, structure and aim of the research forum are described. In addition, we relate this conceptualisation of the research forum to crucial aspects of citizen social science for enabling co-creational research. Second, we introduce a co-created research project that we conducted with multigenerational co-housing projects. In a third step, we present four dimensions of the research forum and our conceptual reflections on their practical application in the cohousing projects to exemplify our methodological framework: opening up spaces, communicative practices, social selfunderstanding and (counter-)public discourses. In conclusion, we summarise our findings and point out the potentials and challenges of the research forum as a methodological foundation for co-creation in citizen social science projects that enhances both the impact of the knowledge produced and the democratisation of science.

\section{The research forum: a methodological framework for co- creation}

The debate is still ongoing about general characteristics of citizen social science as an umbrella term for various approaches from the environmental sciences and from social sciences and humanities (Albert et al., 2021; Kullenberg and Kasperowski, 2016; Tauginiene et al., 2020). In the following section, we present our conceptualisation of the research forum as a methodological framework for face-to-face communication between project partners. We then outline how this conceptualisation relates to four major aspects-participation, transdisciplinarity, impact, and reflexivity-that we consider crucial for co-creational citizen social science.

Conceptualisation. The term "forum" in early Latin means "a place out of doors". The Roman Forum was the public communicative space for citizens and municipal institutions. It was an arena not only for important purposes such as religious practices, court trials, and political speeches, but also for everyday conversation, gossip and discussions among laypeople. The forum can be understood as a communication "marketplace" for 
exchanging perspectives and ideas that provided an opportunity for social participation. According to Jürgen Habermas (1996), the public sphere is constituted through communicative exchange of private perspectives in which public opinions on issues of general interest develop and progress. Despite many exclusionary aspects regarding social status or gender, these early forms of citizen participation in ancient cities eventually led to new forms of democratic self-governance and decision-making. The convergence of private and public opinions via communication has similarities with the scientific aspiration to arrive at generalisable findings.

The research forum is conceptualised as a series of workshops explicitly dedicated to fostering co-creation, co-design and transdisciplinarity across all phases of research-from defining relevant research topics and planning the research, through data collection and data analysis and interpretation, to presentation and evaluation of results. The research forum has a modular structure that takes account of the actual needs of the project in terms of session frequency, focus, format and length. Rules of communication are of crucial importance as an ethical foundation for an appreciative exchange on equal terms between the different project partners. The academic researchers take particular responsibility for ensuring an inclusive and safe environment through moderation and facilitation. The research forum provides the methodological framework for co-designing and applying all kinds of qualitative and quantitative methods, for example, focus groups, photovoice, multilog writing and surveys. In these sessions the general research topic is broken down, reformulated in a set of research questions and transformed into methodical steps for seeking new insights and results. The research forum ensures a collaborative discussion and planning process, so that all research participants can have their say, bring up their perspectives on the topic and be part of the decision-making process regarding research design and methods. By including the perspectives of citizens and civil society, organisations can acquire new insights for developing evidence-based practices.

The research forum sessions are typically structured in accordance with the phases of research. In the first phase, the research forum opens up a space in which co-researcher who share a social concern ideally come together in a "knowledge coalition" to define a research topic. Bonhoure et al. (2019) define a knowledge coalition as "a group including a diversity of relevant actors with diverse experiences and expertise, built to produce socially robust knowledge" (p. 13). The intention of the research forum as a "place out of doors" is that everyone who feels entitled and can contribute to examining the research topic is invited to participate. The second phase is dedicated to conducting research by discussing the different perspectives, collecting data and arriving at generalisable findings, and envisioning evolving social practices. In the third phase, the focus is on a closing discussion in which the results are summarised and the collaborative research process is reflected upon. In a retrospective process evaluation, the academic researchers ask for feedback on and an individual assessment of the progress in acquiring knowledge, deeper selfunderstanding and improvements of social practices. Throughout these phases, the research forum directly serves the aims of citizen social science by fostering: (A) co-creation and co-design of the research process through participation; (B) reflexivity in the planning and realisation process; (C) continuous transdisciplinary exchange, inclusion, transparency and openness; and (D) meaningful and relevant research results with potential for social impact. Participation is addressing the level of engagement of coresearchers, transdisciplinarity focuses on the diversity of stakeholders and their interests, reflexivity is an essential tool for addressing power-relations, and impact focuses on the actual research outcomes.
Participation. Bonney et al. (2009, p. 17; see also Shirk et al., 2012) distinguished between three models for public participation in scientific research, which differ according to the extent to which citizens are involved in steps in the research process: (1) contributory projects, where citizen participation is largely limited to contributing to data collection and recording; (2) collaborative projects, where the involvement of non-scientists also includes data analysis and, possibly, interpretation; (3) co-created projects, where citizen participants are actively involved in most or all steps in the scientific process. In the first two types of participation-contributory and collaborative-citizen scientists are involved merely as research assistants who do not have much say in the planning of the research process. By contrast, cocreation means that citizens participate collaboratively in the decisions regarding the research process (Powell and Colin, 2009). This participatory model could be extended with a fourth category. Whereas Haklay et al. proposed the term "extreme citizen science" (2018) for collaborative, bottom-up research practices, we prefer the term "citizen-led projects", where members of the public assume control and power over the design of the project and thus "take ownership of the research" (Russo, 2012, para. 36). This corresponds to what Sherry Arnstein (1969) called "citizen control as the highest rung on the ladder of citizen participation". It entails a reversal of roles between citizens and experts (Bergold and Thomas, 2012; Sense, 2006). In such projects, it is not the academic researchers who set the research agenda, but rather it is the citizens who initiate and carry out the project and who involve the academic researchers more as enablers and advisers (Evans and Jones, 2004).

As pointed out above, citizen social science regularly aims at addressing urgent social issues through co-creation and co-designas driving principles throughout the entire research project. Research is linked by co-creational formats to experiences and interests of citizens as specialised experts in social concerns, i.e., support for people with mental health issues or with disabilities (Albert et al., 2021, p. 123-124). Co-decision-making begins at the project-design stage, when the research topic and research questions are defined (Bonhoure et al., 2019). It continues throughout the collection, analysis and interpretation of data, and concludes with the presentation of the results. We propose the research forum as a methodological approach that can provide a horizontal, inclusive and safe "communicative space" for different stakeholders in a knowledge coalition. As such, the research forum enables cocreational participation in transdisciplinary scientific knowledge production and deliberation across all phases of research. Cocreation is not only based on ethical considerations but also aims to achieve a different kind of knowledge that is practice-situated, sustainable and socially robust (Franzen and Hilbrich, 2015, p. 28) and can be connected to public debates in society (Hecker et al., 2018). By "socially robust knowledge" (Nowotny, 2003) we understand knowledge that is meaningful for the actual lifeworld of particular communities because it connects specific "situated knowledges" (Haraway, 1988).

Transdisciplinarity. Citizen social science can be characterised as a transdisciplinary science (Fam et al., 2018; Defila and Di Giulio, 2018). Whereas interdisciplinarity presupposes the dismantling of the traditional boundaries between scientific disciplines in favour of an open and multiperspectival view of the research object, transdisciplinarity goes one step further by also involving other social fields from outside the sciences. The concept "transdisciplinarity" refers to different backgrounds, perspectives and agendas of the academic researchers and the co-researchers, which require ongoing reflection (Pettibone et al., 2018). Coresearchers in citizen social science projects have their own 
perspectives and interests regarding the research topic. As a consequence, they have their own say when it comes to topics such as the sustainable development of cities and neighbourhoods, gender equality, youth employment or mental health issues. The reason for this is that the object of research cannot be separated from the genuine life interests and practices of the coresearchers. At the same time science methodologies and theories can complement community skills and knowledge (Fortmann, 2009). When researching and acting in the social lifeworld coincide, the perspectives of those involved in the research cannot be omitted. With "social lifeworld", we refer-following Alfred Schutz and Thomas Luckmann, (1973) - to a concept that highlights the meaning structure inherent in culture and language, which actors create and use to orient themselves towards the social world (Habermas, 1987). If the knowledge to be produced is to have direct and worthwhile consequences for the shaping of the lifeworld and society, it is not enough for actors to simply join in. Science intervenes as a matter of course in political spheres of the lifeworld. Therefore, a transdisciplinary orientation of citizen social science connects with more general discourses on political participation in democratic societies (Thomas, 2021a; Scheller, 2019). However, transdisciplinarity alone does not guarantee the production of socially robust knowledge (Maasen and Lieven, 2006, p. 401). Rather, as pointed out in the section above, ongoing reflection on adequate levels of participation is required.

Reflexivity. Our conception of the research forum refers to Kemmis and McTaggart's "communicative space" (2005, p. 563) as a central element of participatory action research (PAR). Academic researchers and co-researchers plan and discuss their research collaboratively. Deeper and intersubjective understanding of the research object is reached especially by talking, by everyone being able to put their views up for discussion, and by everyone being able to be heard. The overarching aim of the research forum is to achieve a convergence of the different perspectives of all participants in a shared reflection and interpretation of their common reality during the research process. This includes discussing the positionalities, authority, verbalisation skills, expertise and values of the researchers and coresearchers in the joint project (Call-Cummings and Ross, 2019; Bergold and Thomas, 2012). The core of participatory research is constituted not by individual research methods but rather by a certain attitude to incorporating the views and experiences of citizens regarding their own lifeworlds as an inherent part of the research process (Bergold and Thomas, 2020). This does not mean that the whole research process is conducted in a mode of full and deep participation. For pragmatic reasons alone, the academic researchers should be realistic about the amount of time that citizen researchers can devote to scientific endeavours. Nevertheless, the research forum provides the space to discuss with the co-researchers whether and how participation could be intensified. Moreover, the research forum brings to the fore the rich repertoire of social science theories and methodologies that enable the reflection and deconstruction of social reality and its underlying power relations, hierarchies and dichotomies (Thomas, 2021b).

Impact. Citizen social science is not focused solely on theory building and scientific impact but also on the social-and even political-impact on the social lifeworlds of the co-researchers. From our perspective, co-creational citizen social science pursues two aims: first, to integrate lifeworld knowledge into science at all stages of the research process in order to increase scientific knowledge production (Franzen and Hilbrich, 2015); second, to enable co-researchers to achieve findings based on scientific methodologies and theories that are relevant for their everyday life contexts. As intended by applied research, sustainable solutions for practical societal challenges and problems can be created by taking up and deepening knowledge from practice (Aldridge, 2014; Dickinson and Bonney, 2012). "Sustainable" means here that the research-based findings are directly connectable to the meaning, interest and practice structures of the field rather than being thought through by scientists in their academic "ivory towers" without taking adequate account of the logics of the social field-a phenomenon that has been termed "scholastic bias" (Bourdieu, 2000). In the best case, a productive symbiosis arises from a two-sided expansion of knowledge: the expansion of the stock of everyday knowledge and of the archive of social science knowledge. Hence, a convergence of the perspectives of academic researchers and co-researchers does not necessarily mean that scientific standards are trivialised. Rather, as a temporary symbiosis of two perspectives, this collaborative research can meet the needs of both sides: the co-researchers' need for practice-relevant forms of knowledge corresponding with local contexts, and the academic researchers' need for generalised insights and findings (Bergold and Thomas, 2020; Maasen and Lieven, 2006).

\section{Multigenerational co-housing projects: the research forum in practice}

In order to illustrate the practical implementation of the research forum, we provide in what follows background information on a co-created research project that we conducted with three selforganised multigenerational co-housing projects. Three central (research) questions were addressed in the research: How can multigenerational co-housing projects be described as a community beyond traditional bonds such as family, neighbourhood or ethnicity? What community-building processes are characteristic of multigenerational co-housing projects? How can the democratic self-governance of co-housing projects be described? The aim of our research was to extend both the scientific and practical knowledge about how community-building and selforganisation works and can be extended in multigenerational cohousing projects. In the research forum, we wanted to acquire a better understanding of how solidarity and social bonds in cohousing projects work and can be improved.

In this section, we use the term co-researchers for the members of the of self-managed, collectively owned co-housing projects we worked with, and academic researchers or facilitators/moderators to describe ourselves. Besides the organisation of their community life, the groups were characterised by active social exchanges among the various generations: children, adolescents, adults and seniors. The social background of the co-researchers was quite homogeneous because most project members were university graduates and worked in academic jobs-mainly in professions in the social field, such as social worker, teacher or counsellor (Schröder and Scheller, 2017).

For each of the three multigenerational co-housing projects, we organised a series of six joint research workshops over a period of one year. In these 18 sessions, we collaborated with 50 co-housing residents directly and, through wider peer-to-peer methods, with 160 residents in total. The research forum series were structured as follows: first, definition of research topics by the co-researchers; second, conducting of research; third, presentation of research results and final evaluation. Each of the research forum sessions had a thematic focus that was drawn from the pool of topics collected in the first session.

We academic researchers took on the task of substantively and methodologically preparing the respective research forum sessions; in some cases, joint preliminary discussions took place with individual project participants. A wide range of low-threshold, 
creative methods were selected to activate the participants' knowledge and experiences and to reduce barriers to communication by means of work materials that co-researchers produced during the workshop (e.g., posters and photos) and role play as an experimental reflection tool for different standpoints. As experiences and perspectives could also be incorporated in a non-verbal way, this approach facilitated multifaceted participation in the research process that went beyond "just talking". At the end of each session, the co-researchers were usually given "homework"-for example, to conduct biographical interviews-which was to be discussed at the next session. Besides enabling the coresearchers to learn low-threshold research methods, this homework served to involve the residents who had not been able to attend the session in the data collection.

A typical research forum workshop proceeds in six steps: First, we open with a warm-up and a question round about how people are doing; then we present the programme for the day. Each session has a thematic focus that is jointly decided at the previous session. This is followed, second, by the joint evaluation of the "homework" carried out between the sessions. By discussing the community topics and explaining the different perspectives and positions in the house community, shared interpretations of situations emerge. There follows, third, a substantive block on the respective session topic. With the help of various methods, we gather the different views on the topic-for example, strategies for dealing with conflicts. This is usually followed, fourth, by a long mid-day break during which we have lunch together and time for informal conversations. Fifth, in the afternoon, visions about the further development of the project and initial ideas about concrete implementation steps, actions and methods are formulated. Moreover finally, sixth, in the closing plenary session, the process and content of the workshop are summarised. In addition, the topic and the tasks for the following session are discussed, and we ask the co-researchers for substantive and methodological feedback. The entire session is audio-recorded. Quotes given below are excerpts from transcripts of these audio-recordings. In addition, to document the group process and the work materials, videos are recorded and photos taken.

A huge variety of topics were brought up at these workshops, mostly by the members of the co-housing projects. Recurring topics in all three co-housing projects were decision-making and the handling of conflicts within the group. Closely related to the latter topic were explicit and informal rules that guide the everyday life and the interactions in the community. The project members wanted to use the research forum to clarify their visions for the future, to plan new projects for the community and to develop ideas for political interventions in their neighbourhoods and municipality. The relationship and tensions between the individuals and the community were also reflected upon. The project members discussed their needs for private spaces and their interest in joint activities with the whole group, such as summer festivals, group excursions, weekend events, cooking and leisure time activities.

\section{Four dimensions of co-researcher communication}

This section presents our methodological framework of working with the research forum as a key tool for participatory communication, including reflections offered by co-researchers during various methodological feedback rounds throughout the research process. As a result of the methodological conceptualisation of our practical experiences with the research forum as a foundation for co-creation, four key dimensions of co-researcher communication emerged: (1) opening up spaces for social encounters, (2) establishing communicative practices, (3) initiating a process of social self-understanding, and (4) engaging in (counter-)public discourses. From our perspective, these four dimensions resonate with the four crucial aspects of citizen social science discussed above-participation, transdisciplinarity, reflexivity and impact.

The four dimensions derive from the debate on interpretive social science. Habermas shows in "Facts and Norms" how the goal of social understanding among citizens is the driving force of debates on societal problems and issues in the public sphere (1996, pp. 364-366). Nancy Fraser objects that there is not only the public sphere but manyfold of public spheres, which enable less privileged and less powerful citizens getting the opportunity to "find the right voice or words to express their thoughts" (1990, p. 66). In both cases, social self-understanding regarding social situations is a result of citizens debating problems and concerns of common interest. The research forum provides such a "small" public sphere in which participants exchange their views, interrelate their perspectives, and come to agreeable and generalisable definitions of their common situation. Kemmis and McTaggart (2005) implemented this communicative and discursive turn in participatory research methods and conceptualised the research forum as a communicative space for promoting collaborative research with co-researchers. We found that the research forum with its ongoing face-to-face communication fosters co-creational research in citizen social science. In our research, it functioned as such a communicative "place out of doors" for co-creatively negotiating topics of general interest in a participatory way.

Opening up spaces for social encounters. The first task of the research forum is to organise a knowledge coalition to open up a safe space for collaborative research in which a relationship of trust can be developed among all participants (Dentith et al., 2012; Borg et al., 2012). A safe space should not only allow openness, protected communication and mutual respect, but also the expression of different opinions and the articulation of conflicts (Bergold and Thomas, 2012). As the authors stated: "It is not a question of creating a conflict-free space, but rather of ensuring that the conflicts that are revealed can be jointly discussed; that they can either be solved or, at least, accepted as different positions; and that a certain level of conflict tolerance is achieved" (\$13). A steady negotiation process takes place for building mutual trust. Three communication issues must be accordingly addressed and solved in the research forum: "emotional issues," "task issues," and "organisational issues" (Wicks and Reason, 2009, pp. 249-250).

As moderators, we observed the appearance of all three "communication issues" in the research forum. As soon as we became aware that these issues had developed and had become a (latent) topic, we tried to open up a space for a meta-discussion. Further approaches to cope with these issues were that we started each session with a "check-in round" to get into a conversation about emotional attitudes towards that session. We also discussed emotional tensions or hostilities as soon as we became aware of them. Moreover finally, we tried to distribute responsibilities and tasks equally among all participants.

Above all, the research forum aims to provide a space for deliberations that enables the members of the knowledge coalition to take a step back from their everyday lives, from the unquestioned givenness of the social lifeworld from taken-forgranted commonsense interpretations (Schutz and Luckmann, 1973 , p. 3), and from routine practices. During the five-hour sessions, the co-researchers were invited to decentre their everyday interpretations in order to get into a mode of open reflection on their community practices. Instead of gaining new insights driven by pragmatic motives of everyday life for more or less immediate action plans (Berger and Luckmann, 1966), scientific methods offer a different approach. The scientific 
attitude is more about first taking a step back to obtain an overview of the multifaceted complexity of the research topic, and then probing deeper by means of systematic data collection and analyses. While a scientific examination may take years, what is needed in everyday life contexts is a faster clarification of and answer to the questions: "What is at issue here?' and 'What is to be done?". In this way, the co-researchers can develop a new perspective by examining from a distance their everyday practices, thereby gaining both new and-as a result of joint discussions-shared interpretations of their situation.

One of the multigenerational co-housing projects did not have a communal space in the house. To enable the co-researchers from this project to get into a more distanced, explorative and reflexive mode we invited them to our university for the one-day sessions. This gave them an opportunity to step out of the familiar contexts of their community life, which were already interpreted by pre-set meanings, discourses and practices.

Despite our aspiration to open up spaces for social encounters, it was not possible to convince all the residents to participate directly in the collaborative research. The residents who were most active in the research forum were those who were interested in strengthening community and togetherness, and changing the discussion culture. For the most part, the residents who stayed away did so because they rejected the format of "just talking". They had frequently advocated doing practical things instead, such as renovating the house. Moreover, there were different interest factions in the house groups, and we were invited mostly by the faction that wanted to strengthen the community and the discussion culture. This means that by discussing community topics they simultaneously increased their influence in their house project. Opening up spaces must therefore also include critical reflection on, and the potential overcoming of, power structures (Bergold and Thomas, 2012), so that all relevant perspectives can be incorporated into the development of joint, co-created knowledge.

By applying mostly low-threshold methods, we co-designed the research as inclusively as possible for all age groups. In one project, some seniors were unable to participate in the meetings at the university-be it for health reasons or because of scheduling difficulties or personal reservations. Therefore, we arranged an informal meeting with a "seniors' café interview" at their house. Over coffee, cake, and liqueurs, we spent an afternoon with them to talk about community practices and intergenerationality. We brought the transcripts of the interview to the next research forum session to incorporate the absent voices into the research process. To involve children and adolescents in the research forum, we adopted a rather activity-related and play-based approach (Groundwater-Smith et al., 2015). For example, in one method-"visionary thinking" - a story was read out about children who had been allowed to take over and redesign an abandoned house. The children in the co-housing project-aged between 6 and 13 years - could then draw their dream houses and discuss their visions. In another method-“opposites day"-the children discussed how they would live together if they were adults, and the adults reflected on how they would organise the house community if they were children.

"House interviews" were a further method to open up spaces for discussion among all age groups. The residents drafted interview topics and semi-structured interview guides for focused peer-interviews, which they then conducted themselves. In accordance with the principle of co-creation in participatory research, the idea was that the co-researchers should not only collect the data but also choose the topics to be addressed in the interviews. The interview questions were formulated by the residents based on the knowledge, interests, and relevancies of their project. The transcripts of these interviews-and of the workshops-were then fed back into the research forum for the purpose of joint interpretation and analysis. This advanced the substantive development of a common understanding of the research object within the knowledge coalition. Thus, the role of the academic researchers consisted also in contributing to the scientific qualification of the co-researchers by providing inputs on theories and methods.

In summary, the first step of the research forum-opening up a communicative space-was realised through different approaches. Following the idea of a "place out of doors" to achieve a high degree of openness, we applied the following methods: a broad invitation of participants, initiating metadiscussions and check-in rounds, decentring commonsense interpretations and subjective perspectives, stepping out of everyday contexts, and reflections on power imbalances. There is not just one recipe for realising open spaces built on mutual trust. Adequate methods have to be invented for each research project regarding its specific context.

Establishing communicative practices. In addition to opening up spaces, a successful knowledge coalition also presupposes a culture of dialogue and discussion, and, above all, "communicative spaces” (Wicks and Reason, 2009; Kemmis, 2008, p. 135) or "dialogic spaces" (Rowell et al., 2017). Communication across different perspectives aspires to eventually arrive at a shared interpretation of a particular topic. This does not necessarily mean unanimity but rather transparency. The acknowledgement of the wide variety of viewpoints in the room should ideally converge in a broad and inclusive definition of a topic. As Cook (2012) noted: "If authentic involvement is to take place, considerable time and effort needs to be allocated during the research process to "just talking". ... Talking was fundamental to moving beyond general conceptualisations of practice to deeper understandings" (para. 32). A "just talking" approach should be combined with other methodological instruments (e.g., writing, painting, drawing, playing games, drama) that enable the coresearchers to creatively take a step back from their everyday lives and to express their perspectives on the research topic.

Keeping the communicative spaces open was made more difficult by the fact that, because of the different social statuses and communication skills of the members of the house groups, there were always some residents who found it easier to turn their positions into group consensus. Other people-especially residents already in a marginal position within the group-found it considerably harder to make their perspectives heard. Moreover, personal conflicts between residents may have been a barrier for some to engage in the research forum, and these conflicts sometimes erupted in the sessions. Here, the set of communication rules proved fundamental in preventing the sessions from turning into an arena for personal conflicts. Furthermore, creating maximum transparency about topics and results of the research forum for all residents helped us to avoid getting caught up in the politics of the co-housing projects. Therefore, all materials produced in the sessions were made available to all residents, also to those who had not been present. The research methods expanded the communication space beyond the actual sessions by inviting all residents to contribute to the data collection, for example, through peer-interviews, surveys and feedback rounds.

As already pointed out, a self-reflexive moderation of the sessions was important for keeping the communicative space open. Moderation is a two-edged sword: it is an instrument of domination and an opportunity for equalising inequalities and levelling power hierarchies. Asymmetry between the positions of the various speakers is a starting premise of the research forum. 
In particular, those speakers who have good speaking skills, a high ability to articulate themselves, and previous experience of communicative group processes may exert a strong influence on the consensus-finding process. One thing that was especially problematised by the co-researchers with regard to power processes and hierarchies was the talk-heavy format. As one participant put it:

And I believe that it is the discussion format, and it is also an academic format, where Person $\mathrm{A}$ is quite steady in the saddle and can also express himself quite well. And Person $\mathrm{B}$ is a completely different type. He would be quite out of his depth here, or he would be worried that he was going to be out of his depth. (Participant in Workshop 2, CoHousing Project A, 2016; translated from German)

Our main strategy for countering domination and the exclusion of perspectives in the research forum was to have a strong forum moderator who paid attention to turn-taking and, if necessary, intervened when substantive disagreements and conflicts arose among the residents. Although it was not possible for the moderators to take a neutral stance because of their own research interests, they took a position outside the heterogeneous interests in the co-housing project. As outsiders, we found it easier to maintain an overview and to ensure that all perspectives could be articulated. However, the disadvantage was that hierarchies between academic researchers and co-researchers may have been consolidated. As a basic strategy to avoid pitfalls such as pushing selective topics that are relevant only from the academic researchers' point of view, the moderators obtained a mandate from all those present, and renewed it again and again. At the end of each workshop the moderators asked the coresearchers about their priorities for the upcoming sessions to ensure the relevance of the proposed topics. Moreover, they endeavoured to achieve a good balance between keeping their decisions explicit and discussable and ensuring that work progressed in a focused way.

Consequently, the research forum is an ongoing attempt of opening doors to each other's contribution by establishing a space for communication and dialogue. It is important to consider different communication skills, the implementation of shared communication rules, a high degree of transparency, and a selfreflexive moderation that enables mutual decision-making.

Initiating a process of social self-understanding. Another central aspect of the research forum that corresponds with participatory social research is the initiation of a process of social selfunderstanding via social exchange and communication (Thomas, 2021a). Members of the knowledge coalition share their perspectives in the "communicative marketplace" of the forum, in order to develop generalisable definitions of situations and define issues of shared interest to be further progressed throughout the research process. The research forum thus provides a space for group discussion that becomes the central instrument for the collection and interpretation of data. In contrast to group discussions, the research forum is not a "one-off encounter" of communicative exchange, but aims at initiating a discourse of social self-understanding in the various sessions.

With the concept of social self-understanding, we want to conceptualise the central aim of the communication about the research topic between all participants in the research forum. It starts with the everyday life interpretations of the co-researchers, in which they already apprehend their situation and their practices. We use these first-order interpretations (Schutz, 1973) to initiate a process of deeper self-understanding of what is already established as lived reality. Community, gender, age and the housing project do not exist as predefined realities but rather as sociocultural meanings that are the result of negotiation in contextualised social practices. We use the term selfunderstanding in the way that Giddens introduced it into social science discourse in the UK. Drawing on the German discussion on hermeneutics and interpretation (Habermas, 1985), Giddens (1976) wrote: "Hermeneutics, on the other hand, is directed to understanding the participation of actors in an intersubjective "form of life" and hence to an interest in improving human communication or self-understanding" (p. 60). Selfunderstanding aims therefore at emancipation from forces that are present and effective in situations but are not comprehended by the actors (Habermas, 1985). With the prefix "social", we want to stress that self-understanding is not achieved in workshops by individual reflections or psycho-therapeutic processes, but rather by relating experiences and perspectives to each other in mutual communicative exchange.

The challenge of initiating a discourse of social selfunderstanding consists in creating a forum in which the subjective experiences of reality do not remain unmediated and external to each other. What can count as a community, what should be achieved in that community, and how the community and daily life in the co-housing project can be organised are questions that presuppose mutual understanding and agreement among the project members. Through dialogue and discussion, the participants should be able not only to communicate but to transcend the boundaries of their subjective attitudes and together in shared definitions of their reality. It is a question of developing a generalisable viewpoint in which the differences and divergences between the subjective perspectives can be grasped. Scientific methods contribute to overcoming the particularity of individual perspectives and achieving generalisable knowledge. By slowing down the pace, a productive discussion can succeed. This proceeds in a process of mutual translation that takes the subjective perspectives and interpretations as a starting point and transforms them into generalised knowledge. Social selfunderstanding is therefore both about articulating individual points of view and engaging in consensual discussions to create "collective knowledge" in which the individual contributions are integrated and reflected at the same time (Ansell et al., 2012, p. 175).

Community-building practices were one of the central topics in our research project. The first step was that everyone was given an opportunity to express their individual perspectives on topics such as: What is a community? What kind of community should be realised in the co-housing project? How much community is desirable? The next step was to synthesise a mutual understanding of the community in consensus among the residents. Aspects addressed included the structure of house meetings; the way decisions are to be made; and ideas on the general mission of multigenerational co-housing projects, such as environmental sustainability, the revitalisation of rural villages, non-violent communication, etc. Finally, not only did everyone have to agree in general to this common definition of community, they should also have been able to have their concrete visions for practical action plans included in it.

In these various reflection steps, every member of the knowledge coalition gets a better understanding of their own ideas by interrelating the particularity of their individual perspectives to an emerging consensual definition. Social selfunderstanding is reached when a generalisable definition of the current situation and mission of the group has been developed. Instead of all co-researchers maintaining their individual points of view, social self-understanding aims to develop a common definition of what can be considered to be the shared social reality of the research group. From our perspective, this is precisely what 
the research forum would provide for citizen social science: collaborative work on common interpretations of reality, and options for action that encompass both the particularity of the individuals' own standpoints and a generalisable finding regarding social reality.

Scientific methods constitute tools for decentring the particularities of individual perspectives and achieving generalisable research results. The main difficulty that the residents faced when researching their own house communities was to temporarily suspend their personal positions and opinions. Clearly, community and intergenerationality were not neutral topics in the co-housing projects but always included a normative dimension. Negotiations in the research forum were also always a matter of internal politics because collective decisions in the co-housing projects are driven by mutually shared interpretations and definitions of situations. Especially in the case of controversial topics-such as different forms and levels of engagement in the community-there was always a struggle to find the "right" interpretation of the situation. For co-researchers, the possibility arose that their own positions and interests in the co-housing community would be strengthened or weakened by the "right" or "wrong" definition achieved in the research forum. The research forum can develop its qualities to full potential if the communicative situation is kept open until the divergent positions and perspectives have been mediated to such an extent that the perspectives of all participants have been taken into account in a consensual definition-or at least a mutual understanding of the particular differences has been reached.

We see community-building as an intrinsic part of citizen social science (Albert et al., 2021, p. 127). The extent to which the research forum contributed to community-building among the residents of the multigenerational co-housing projects depended on how successful we were in involving those who did not attend the workshop sessions. In principle, we found that those who attended gained a knowledge advantage over those who did not participate-despite the "homework" and the sharing of generated data and materials. Against this background, our inclusion strategy failed due to the fact that, when it came to gaining mutual understanding and agreement, there was no substitute for actual participation in a five-hour session. As one co-researcher put it:

I suddenly had the feeling that there was a rift between those who were there and those who weren't. A process had taken place. And it was perceived by those who were there as important, somehow. And we can't seem to manage to convey the insights that we gained there to the others. (Participant in Workshop 2, Co-Housing Project A, 2016; translated from German)

This quotation stresses the crucial fact that the research forum itself became a community-building process, for which it was necessary to personally take part. Expressing one's own position and listening to and acknowledging the positions of others constitutes a prerequisite for a convergence between, and recognition of, disparate positions as a basis for reaching consensus. So how can one deal with the challenge that community can hardly be shaped in absentia? The moderators can explicitly point out this fact at the co-design stage in order to seek ways and means to involve the absentees in the community-building co-creational research process. As described above, using methods such as peer-interviews and surveys to expand the communicative space beyond the research forum sessions would still be a prerequisite. Therefore, the research forum offers a "communicative marketplace" in which citizens engage to develop new perspectives, whereas science provides methods to facilitate consensus leading to generalisable definitions and results.

Engaging in (counter-)public discourses. Social selfunderstanding is not merely a knowledge-building process limited to knowledge acquisition in the research forum and to the community of co-researchers who are directly involved. By cocreating empirically and socially robust knowledge that is grounded in the co-researchers' lifeworlds and can also be used externally to gain political influence in social discourses, citizen social science can gain both-impact inside and outside the co-researcher groups. It is not only about internal capacity building but alsofollowing the tradition of participatory action research-a way that could initiate public engagement beyond the research forum. Therefore, such knowledge production explicitly seeks to have an impact on social practices by initiating and expanding the deliberative discussions beyond research in the public sphere (Kemmis et al., 2014, pp. 48-50). Citizen social science can make a contribution to everyday practice and the public sphere, which Jürgen Habermas (1974) defined as "a realm of our social life in which something approaching public opinion can be formed," a realm in which citizens have "the freedom to express and publish their opinions" and to "confer in an unrestricted fashion ... about matters of general interest" (p. 49). Against this background, counter-public discourse engages with the public realm by contrasting and even challenging the status quo of any hegemonic argument. In that regard, counter-publics constitute „parallel discursive arenas where members of subordinated social groups invent and circulate counter-discourses, which in turn permit them to formulate oppositional interpretations of their identities, interests, and needs" (Fraser, 1990, p. 67). In the research forum, the participants try to go beyond the commonsense interpretations of social reality and to come up with a new understanding of their lived reality and possibilities for action.

In the research forum, the co-housing groups developed a common voice and (re-)articulated aspirations to take action and participate in public discourse. By reaching a comprehensive understanding of their situation across their individual points of view, the co-researchers analysed ideas and visions that transcended the boundaries of the private or semi-private spaces of the co-housing communities. Their rather particular visions of commoning, community living, intergenerationality, affordability, economic, social and ecological sustainability, and urban and cultural development have been externalised in the wider local and city-wide public sphere by politically active community members.

Engagement in public discourse and possibilities of political action by the co-housing projects explicitly became a topic that was discussed in the research forum. For example, a member of the board of Co-Housing Project A actively participated regularly in information and discussion events on urban policy, where he shared his experiences during the conceptualisation, purchase and construction phases of the project and on its current status. In a sense, he became a spokesperson in the regional public discussion about multigenerational co-housing by drawing attention to the difficult conditions for the implementation of this model. In Co-Housing Project B, the multigenerational cohousing project was presented as a flagship for innovative living arrangements at political conferences and local housing policy events. The group aimed to gain trust for the unknown model at the political and urban planning levels (Workshop 1, Co-Housing Project B, 2017). The protagonists advocated increased support for multigenerational co-housing projects on a rental basis, and called on municipal housing associations to adapt the model accordingly. One workshop participant asked: 
I would be interested to know how concrete the intentions of the municipal housing associations in Potsdam and Frankfurt/Oder are with regard to these multigenerational co-housing in high-rise buildings projects .... Is what we say here of any relevance at all? Do these municipal housing associations even want to hear about experiences? (Participant in Workshop 1, Co-Housing Project B, 2017; translated from German)

Co-Housing Project $\mathrm{C}$ expressed the aspiration to make the house known in the rural municipality and to get more involved in local community work, for example, by erecting benches or setting up an organic community store (Workshop 5, CoHousing Project C, 2018). The residents in Co-Housing Project D discussed the lethargy in the substantive engagement with fundamental political questions relating to the project concept that had emerged during the ten years of the project's existence. Reflecting upon substantive re-orientation included a stronger engagement in political discourse as a project (Workshop 2, CoHousing Project D, 2018).

Local communities and politics also influenced the discussions within the projects. For Project A and Project D, it was important to develop a shared (political) self-image as a common identity across the topics of community, multigenerationality and ecology. In the case of Project $\mathrm{B}$ and Project $\mathrm{C}$, it was a question of developing socio-political potency in order to exert an influence in the municipality and the city-for example, on multigenerational co-housing on a rental basis or the participatory ecological shaping of the rural village. And finally, Project $C$ developed political ideas for a "socially just city" in which the general public could also have access to innovative forms of housing.

Overall, different counter-public discourses were initiated by the projects and through the deepening of the social selfunderstanding of their community practices in the research forum. These counter-public discourses are formed through the discussion of the social and political boundaries and limitations of the co-researchers' ability to act in their lifeworlds. A counterpublic is constituted in order to develop prospects for the expansion of "spaces of possibility" (Fraser, 1990). Thus, knowledge and discussions within the projects did not have only an internal effect on the co-housing communities. Rather, by transforming their private attitudes, opinions and interests into a generalisable knowledge and action perspective, they gained a voice as a project and thus became constituted as political subjects in the public sphere. Against the background of rising rents and isolation, they developed political agency to promote multigenerational co-housing as an alternative concept for an affordable, self-determined, solidaric housing commons (Schröder and Scheller, 2017). The research forum can go beyond the boundaries of "just doing research" within the knowledge coalition. The co-researchers can use their new knowledge and understanding of their social situation to engage in (counter-) public discourses aiming for social transformations and change.

\section{Conclusion: the research forum as a methodological foundation for co-creation}

The intention of this paper was to introduce the research forum as a methodological framework for co-researcher communication that enables co-creation in citizen social science projects. We developed the argument that intentional, self-reflective forms of communication between the members of the knowledge coalition enhance the engagement of co-researchers throughout all phases of research. The research forum provides a methodological framework that ensures that the perspective of the co-researchers on their own social lifeworlds is taken into account in all phases of research-from the definition of the research topic, through the research process, to the final presentation and evaluation of the research findings. Reflecting on our expertise in co-creational research with residents of multigenerational co-housing projects, we illustrated how the methodological aspirations played out in practice in four dimensions: opening up spaces for social encounters, establishing communicative practice, initiating a process of social self-understanding, and engaging in (counter-) public discourses. These four dimensions resonate with four aspects that we consider crucial for co-creation in citizen social science: (A) participation, (B) transdisciplinarity, (C) reflexivity and (D) impact:

(A) As a communicative space for knowledge-coalition building, collective decision-making and mutual discussions, the research forum ensured a process of comprehensive participation and engagement of co-researchers in the research. This required, first and foremost, consensus about basic communication rules and moderation to ensure a safe and horizontal space. Co-researchers were positioned at the centre of the research across all phases.

(B) Through communication, the different perspectives on community practices and mutual support became discussable. In this way, the research forum provided a space for new transdisciplinary perspectives between ourselves and the co-researchers. However, despite achieving a convergence of different perspectives in a generalisable finding, it became clear that the individual particularities would also need to be respected, especially when it came to reflecting on conflicts.

(C) By working with social science methodologies and theories, the co-researchers could take a step back and communicate beyond the routines of everyday life. Here, the distancing and generalising potential of science was put into practice in order to come up with research findings about the community practices in each co-housing project. The circular transcending process started from situated local knowledge, which was generalised through co-created research and then fed back into the local context in the form of changed, new knowledge.

(D) The research results achieved not only a scientific impact on the theoretical discourse about community processes and co-housing but also a social impact on the co-researchers' lifeworlds. On the one hand, the research led to the compilation of a handbook focusing on communitybuilding processes in multigenerational co-housing projects (Thomas et al., 2020). On the other hand, the knowledge was translated into explicit community-building actions within and outside the co-housing projects. Moreover, the findings of the co-created research could also achieve a political impact if they were connected with public discourses about alternative forms of affordable, selfdetermined housing.

In summary, the research forum as a methodological framework for co-creation in citizen social science projects provides a communicative space for mutual exchange, planning, discussion and learning. As such it contributes to the democratisation of science because it consistently opens up the discussion about subjects and objects of research. It connects social science with actual social concerns of co-researchers and vice versa. Ideally, the knowledge produced can simultaneously contribute to scientific, social and political discourses. Particularly important for co-creational research is the inclusion of co-researchers and their perspectives from the very beginning of a project-be it by means of co-design of the research topic and research questions (Bonhoure et al., 2019) or co-evaluation (Mayer et al., 2021). Ambitions for co-creation may sometimes fail, and may not take off 
after the first meeting. In the best case, however, the research forum yields rigorous, evidence-based new knowledge for both sides-pragmatic reflexive knowledge for the co-researchers in order to enhance their ability to act, and practice-saturated knowledge that the academic researchers can use for in-depth analysis in order to make a theoretical contribution to expanding the archive of scientific knowledge.

\section{Data availability}

The datasets generated during and/or analysed during the current study are housed at the corresponding authors' primary institution in Germany and are also available from the corresponding author on reasonable request.

Received: 14 July 2020; Accepted: 13 September 2021;

Published online: 21 October 2021

\section{References}

Albert A, Balázs B, Butkevičienè E, Mayer K, Perelló J (2021) Citizen social science: new and established approaches to participation in social research. In: Vohland K, Land-zandstra A, Ceccaroni L, Lemmens R, Perelló J, Ponti M, Wagenknecht K (eds) The science of citizen science. Springer International Publishing, Basel, pp. 119-138

Aldridge J (2014) Working with vulnerable groups in social research: dilemmas by default and design. Qual Res 14(1):112-130. https://doi.org/10.1177/ 1468794112455041

Ansell N, Robson E, Hajdu F, van Blerk L (2012) Learning from young people about their lives. Using participatory methods to research the impacts of AIDS in southern Africa. Child Geogr 10(2):169-186

Arnstein SR (1969) A ladder of citizen participation. J Am Inst Plan 35(4):216-224. https://doi.org/10.1080/01944366908977225

Berger PL, Luckmann T (1966) The social construction of reality: a treatise in the sociology of knowledge. Anchor Books, Garden City, NY

Bergold J, Thomas S (2012) Participatory research methods: A methodological approach in motion. Forum Qualitative Sozialforschung/Forum: Qualitative. Soc Res 13(1):191-222. https://doi.org/10.17169/fqs-13.1.1801

Bergold J, Thomas S (2020) Partizipative Forschung (Participatory research). In: Mey G, Mruck K (eds) Handbuch qualitative forschung in der psychologie. Springer, Wiesbaden, pp. 1-21. https://doi.org/10.1007/978-3-658-18387-5 25-2

Bonhoure I, Cigarini A, Vicens J, Perelló J (2019) Citizen social science in practice: a critical analysis of a mental health community-based project. Preprint, 24 October. SocArXiv. Available at: https://osf.io/63aj7. Accessed 19 June 2020

Bonney R, Ballard H, Jordan R et al. (2009) Public participation in scientific research: defining the field and assessing its potential for informal science education. A CAISE inquiry group report. Center of Advancement of Informal Science Education (CAISE), Washington, D.C, Available at: https:// eric.ed.gov/?id=ED519688. Accessed 4 Feb 2020

Bonney R, Shirk JL, Phillips TB, Wiggins A, Ballard HL, Miller-Rushing AJ, Parrish JK (2014) Next steps for citizen science. Science 343(6178):1436-1437. https://doi.org/10.1126/science.1251554

Borg M, Karlsson B, Kim HS, McCormack B (2012) Opening up for many voices in knowledge construction. Forum Qual Sozialforschung 13(1). https://doi.org/ $10.17169 /$ fqs-13.1.1793

Bourdieu P (2000) Pascalian meditations. Polity Press, Cambridge

Call-Cummings M, Ross K (2019) Re-positioning power and re-imagining reflexivity: examining positionality and building validity through reconstructive horizon analysis. In: Strunk KK, Locke A (eds) Research methods for social justice and equity in education. Springer International Publishing, Cham, pp. 3-13. https://doi.org/10.1007/978-3-030-05900-2_1

Cook T (2012) Where participatory approaches meet pragmatism in funded (health) research: the challenge of finding meaningful spaces. Forum Qual Sozialforschung 13(1). https://doi.org/10.17169/fqs-13.1.1783

Dadich A (2014) Citizen social science: a methodology to facilitate and evaluate workplace learning in continuing interprofessional education. J Interprof Care 28(3):194-199. https://doi.org/10.3109/13561820.2013.874982

Darch P (2017) When scientists become social scientists: how citizen science projects learn about volunteers. Int J Digi Curat 12(2):61-75. https://doi.org/ $10.2218 / \mathrm{ijdc}$.v12i2.551

Defila R, Di Giulio A (2018) What is it good for? Reflecting and systematizing accompanying research to research programs. GAIA 27(1):97-104. https:// doi.org/10.14512/gaia.27.S1.17
Dentith AM, Measor L, O'Malley MP (2012) The research imagination amid dilemmas of engaging young people in critical participatory work. Forum Qual Sozialforschung 13(1). https://doi.org/10.17169/fqs-13.1.1788

Dickinson JL, Bonney RE (2012) Citizen science: public participation in environmental research. Cornell University Press, Ithaca, NY

Eitzel MV, Cappadonna JL, Santos-Lang C et al. (2017) Citizen science terminology matters: exploring key terms. Citizen Sci 2(1):1-20. https://doi.org/10.5334/ cstp. 96

Eleta I, Clavell GG, Righi V et al. (2019) The promise of participation and decisionmaking power in citizen science. Citizen Sci 4(1):8. https://doi.org/10.5334/ cstp. 171

Evans C, Jones R (2004) Engagement and empowerment, research and relevance: comments on user-controlled research. Res Policy Plan 22(2):5-13

Fam D, Neuhauser L, Gibbs P (eds) (2018) Transdisciplinary theory, practice and education: the art of collaborative research and collective learning. Springer International Publishing, Cham, Available at Accessed 16 January 2020. https://www.springer.com/gp/book/9783319937427

Franzen M, Hilbrich I (2015) Forschen in Gesellschaft: Citizen Science als Modell für die Sozialwissenschaften? WZB Mitteilungen Heft 150. WZB, Berlin, Available at Accessed 19 June 2020. https://bibliothek.wzb.eu/artikel/2015/f 19459.pdf

Franzoni C, Sauermann H (2014) Crowd science: the organization of scientific research in open collaborative projects. Res Policy 43(1):1-20. https://doi.org/ 10.1016/j.respol.2013.07.005

Fraser N (1990) Rethinking the public sphere: a contribution to the critique of actually existing democracy. Social Text 25/26:56-80. https://doi.org/10.2307/ 466240

Fortmann L (ed) (2009) Participatory research in conservation and rural livelihoods: doing science together. John Wiley \& Sons, Oxford

Groundwater-Smith S, Dockett S, Bottrell D (2015) Participatory research with children and young people. SAGE, London, 10.4135/9781473910751

Giddens A (1976) New Rules of Sociological Method: A Positive Critique of Interpretive Sociologies. Basic Books, New York

Habermas J (1985) The theory of communicative action, Volume 2: Lifeworld and system: a critique of functionalist reason. Beacon Press, Boston

Habermas J (1974) The public sphere: an encyclopedia article. New Ger Crit 3:49-55. https://doi.org/10.2307/487737

Habermas J (1987) Knowledge and human interest. Beacon Press, Boston

Habermas J (1996) Between facts and norms. MIT Press, Cambridge

Haklay M (2018) Participatory citizen science. In: Hecker S, Haklay M, Bowser A, et al., (eds) Citizen science: innovation in open science, society and policy. UCL Press, London, pp. 52-62

Haraway D (1988) Situated knowledges: the science question in feminism and the privilege of partial perspective. Femin Stud 14:575-599

Hecker S, Haklay M, Bowser A, Makuch Z, Vogel J, Bonn A (eds) (2018) Citizen science: innovation in open science, society and policy. UCL Press, London

Heiss R, Matthes J (2017) Citizen science in the social sciences: a call for more evidence. GAIA 26(1):22-26. https://doi.org/10.14512/gaia.26.1.7

Irwin A (1995) Citizen science: a study of people, expertise and sustainable development. Routledge, London

Kasemir B, Jäger J, Jaeger CC, Gardner MT (2003) Public Participation in Sustainability. Science: a handbook. Cambridge University Press, Cambridge

Kemmis S (2008) Critical theory and participatory action research. In: Reason P Bradbury H (eds) The sage handbook of action research. Sage, London, pp. 121-138. https://doi.org/10.4135/9781848607934

Kemmis S, McTaggart R (2005) Participatory action research. Communicative action and the public sphere. In: Denzin NK, Lincoln YS (eds) Handbook of qualitative research. Sage, Thousand Oaks, CA, pp. 559-603

Kemmis S, McTaggart R, Nixon R (2014) The action research planner: doing critical participatory action research. Springer, New York, NY

Kullenberg C, Kasperowski D (2016) What is citizen science? A scientometric meta-analysis. PLoS ONE 11(1):1-16. https://doi.org/10.1371/ journal.pone. 0147152

Kythreotis AP, Mantyka-Pringle C, Mercer TG et al. (2019) Citizen social science for more integrative and effective climate action: a science-policy perspective. Front Environ Sci 7:10. https://doi.org/10.3389/fenvs.2019.00010

Leshner AI (2003) Public engagement with science. Science 299(5609):977-977. https://doi.org/10.1126/science.299.5609.977

Maasen S, Lieven O (2006) Transdisciplinarity: a new mode of governing science? Sci Public Policy 33(6):399-410. https://doi.org/10.3152/147154306781778803

Mayer K, Kieslinger B, Schäfer T (2018) Open and participatory citizen social science for evidence-based decision making. In: Heigl F, Dörler D, Ernst M (eds) Austrian Citizen Science Conference 2018. Frontiers Media SA, Lausanne, pp. 74-77. Available at https://www.frontiersin.org/books/ Austrian_Citizen_Science Conference 2018/1719. Accessed 19 June 2020

Mayer K, Kieslinger B, Schäfer T (2021) Co-evaluation: re-situating participatory social research in citizen social science. Human Soc Sci Commun (in press) 
Nowotny H (2003) Democratising expertise and socially robust knowledge. Sci Public Policy 30(3):151-156

Ottinger G (2010) Buckets of resistance: standards and the effectiveness of citizen science. Sci Technol Human Val 35(2):244-270. https://doi.org/10.1177/ 0162243909337121

Pettibone L, Ziegler D (2016) Citizen science: Bürgerforschung in den Geistes- und Kulturwissenschaften (Citizen science: citizen research in the humanities and cultural sciences). In: Smolarski R, Oswald K, Kalus M (eds) Bürger Künste Wissenschaft: Citizen Science in Kultur und Geisteswissenschaften (Citizen arts science: citizen science in culture and humanities). Computus, Gutenberg, pp. 57-69. 10.22032/dbt.39056

Pettibone L, Blättel-Mink B, Balázs B et al. (2018) Transdisciplinary sustainability research and citizen science: options for mutual learning. GAIA 27(2):222-225(4). https://doi.org/10.14512/gaia.27.2.9

Phillips TB, Ballard HL, Lewenstein BV, Bonney R (2019) Engagement in science through citizen science: moving beyond data collection. Sci Educ 103(3):665-690. https://doi.org/10.1002/sce.21501

Powell MC, Colin M (2009) Participatory paradoxes: facilitating citizen engagement in science and technology from the top-down? Bull Sci Technol Soc 29(4):325-342

Purdam K (2014) Citizen social science and citizen data? Methodological and ethical challenges for social research. Curr Sociol 62(3):374-392. https:// doi.org/10.1177/0011392114527997

Russo J (2012) Survivor-controlled research: a new foundation for thinking about psychiatry and mental health. Forum Qual Sozialforschung 13(1). https:// doi.org/10.17169/fqs-13.1.1790

Rowell LL, Riel MM, Polush EYU (2017) Defining action research: on dialogic spaces for constructing shared meanings. In: Rowell LL, Bruce CD, Shosh JM, Riel MM (eds) The palgrave international handbook of action research. Palgrave Macmillan, New York, NY, pp. 85-101

Sauermann H, Vohland K, Antoniou V, Balázs B et al. (2020) Citizen science and sustainability transitions. Res Policy 49(5):103978. https://doi.org/10.1016/ j.respol.2020.103978

Scheller D (2019) Demokratisierung der Postdemokratie: Städtische soziale Bewegungen in Berlin und New York City (Democratization of postdemocracy Urban social movements in Berlin and New York City). transcript, Bielefeld

Schröder S, Scheller D (2017) Abgesicherte Fürsorge und fürsorgliche Absicherung in Gemeinschaft. Mehrgenerationenwohnprojekte als neue Formen der städtischen Reproduktion? (Secured care and caring protection in community. Multi-generational housing projects as new forms of urban reproduction?). sublurban. zeitschrift für kritische stadtforschung 5(3):23-42

Schutz A (1973) Collected papers I. The problem of social reality. Nijhof, The Hague

Schutz A, Luckmann T (1973) The structures of the life-world. Northwestern University Press, Evanston, IL

Senabre E, Ferran-Ferrer N, Perelló J (2018) Participatory design of citizen science experiments. Comunicar 26(54):29-38. https://doi.org/10.3916/C54-2018-03

Senabre-Hidalgo E, Perelló J, Becker F, Bonhoure, I, Legris M, Cigarini A (2021) Participation and co-creation in citizen science. In Vohland $\mathrm{K}$, LandZandstra A, Ceccaroni L et al. (eds), The science of citizen science. Springer, Basel, pp. 199-218

Sense AJ (2006) Driving the bus from the rear passenger seat: control dilemmas of participative action research. Inte J Soc Res Methodol 9(1):1-13. https:// doi.org/10.1080/13645570500435546

Shirk J, Ballard H, Wilderman C et al. (2012) Public participation in scientific research: a framework for deliberate design. Ecol Soc 17(2). https://doi.org/ 10.5751/ES-04705-170229

Tauginienè L, Butkevičiene E, Vohland K et al. (2020) Citizen science in the social sciences and humanities: the power of interdisciplinarity. Palgrave Commun 6(1):1-11. https://doi.org/10.1057/s41599-020-0471-y

Thomas S (2021a) Wahrheit und Vernunft. Das Research Forum als methodologischer Rahmen partizipativer Forschung (Truth and reason. The research forum as a methodological frame for participatory research). In: Flick S,
Herold A (eds) Zur Kritik der partizipativen Forschung. Forschungspraxis im Spiegel der Kritischen Theorie. Beltz/Juventa, Weinheim, pp. 41-64

Thomas S (2021b) Partizipative Forschung mit Kindern und Jugendlichen. Ein methodischer Überblick. (Participatory research with children and youth. A methodical overview). In: Thomas S, Rothmaler J, Hildebrandt F, Budde R, Pigorsch S (eds) Partizipation in der Bildungsforschung, 2nd ed. Beltz/ Juventa, Weinheim, pp. 16-66

Thomas S, Scheller D, Ehmann T, Schröder S (2020) Mehrgenerationenwohnen: Ein Leitfaden für Gemeinschaft und solidarisches Zusammenleben (Multigenerational co-housing: a guide to community and living together in solidarity). BoD, Norderstedt

Vohland K, Land-Zandstra A, Ceccaroni L et al. (2021) (eds) The science of citizen science. Springer, Basel

Whyte WF (ed) (1990) Participatory action research. Sage focus editions. Sage, Newbury Park, California

Wicks PG, Reason P (2009) Initiating action research: challenges and paradoxes of opening communicative space. Action Res (Lond) 7(3):243-262. https:// doi.org/10.1177/1476750309336715

\section{Acknowledgements}

We are very thankful to all co-researching co-housing residents for their time, commitment, and openness. We also thank our translator and proofreader, Miriam Geoghegan. The research project was funded by the German Federal Ministry of Education and Research under funding code 13FH009SX5 (2016-2019). The translation and proofreading was realised through CoAct. The CoAct project has received funding from the European Union's Horizon 2020 research and innovation programme under grant agreement number 873048 . Open Access was funded by the German Federal Ministry of Education and Research under funding code 16PGF0273.

\section{Funding}

Open Access funding enabled and organized by Projekt DEAL.

\section{Competing interests}

The authors declare no competing interests.

\section{Additional information}

Correspondence and requests for materials should be addressed to Stefan Thomas or David Scheller.

Reprints and permission information is available at http://www.nature.com/reprints

Publisher's note Springer Nature remains neutral with regard to jurisdictional claims in published maps and institutional affiliations.

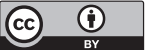

Open Access This article is licensed under a Creative Commons Attribution 4.0 International License, which permits use, sharing, adaptation, distribution and reproduction in any medium or format, as long as you give appropriate credit to the original author(s) and the source, provide a link to the Creative Commons license, and indicate if changes were made. The images or other third party material in this article are included in the article's Creative Commons license, unless indicated otherwise in a credit line to the material. If material is not included in the article's Creative Commons license and your intended use is not permitted by statutory regulation or exceeds the permitted use, you will need to obtain permission directly from the copyright holder. To view a copy of this license, visit http://creativecommons.org/ licenses/by/4.0/.

(c) The Author(s) 2021 